OPEN ACCESS

Edited by:

Zsolt Illes,

University of Southern Denmark

Odense, Denmark

Reviewed by:

Izumi Kawachi

Niigata University, Japan Masaaki Niino,

National Hospital Organization, Japan

*Correspondence: Kazem Zibara

kzibara@ul.edu.Ib

Naser Farhad

naserfarhadi42@yahoo.com

Specialty section:

This article was submitted to

Multiple Sclerosis and

Neuroimmunology,

a section of the journal

Frontiers in Immunology

Received: 30 June 2018 Accepted: 08 October 2018 Published: 30 October 2018

Citation:

Ghareghani M, Reiter RJ, Zibara K and Farhadi N (2018) Latitude, Vitamin D, Melatonin, and Gut Microbiota Act in Concert to Initiate Multiple Sclerosis: A New Mechanistic Pathway. Front. Immunol. 9:2484 doi: 10.3389/fimmu.2018.02484

\section{Latitude, Vitamin D, Melatonin, and Gut Microbiota Act in Concert to Initiate Multiple Sclerosis: A New Mechanistic Pathway}

\author{
Majid Ghareghani ${ }^{1,2}$, Russel J. Reiter ${ }^{3}$, Kazem Zibara ${ }^{4 *}$ and Naser Farhadi ${ }^{5 *}$ \\ ${ }^{1}$ CERVO Brain Research Center, Quebec City, QC, Canada, ${ }^{2}$ Medicinal Plants Research Center, Yasuj University of Medical \\ Sciences, Yasuj, Iran, ${ }^{3}$ Department of Cell Systems and Anatomy, The University of Texas Health Science Center, San \\ Antonio, TX, United States, ${ }^{4}$ PRASE, Biology Department, Faculty of Sciences-I, Lebanese University, Beirut, Lebanon, \\ ${ }^{5}$ Cellular and Molecular Research Center, Yasuj University of Medical Sciences, Yasuj, Iran
}

Multiple sclerosis (MS) is an inflammatory demyelinating disease of the central nervous system (CNS). While the etiology of MS is still largely unknown, scientists believe that the interaction of several endogenous and exogenous factors may be involved in this disease. Epidemiologists have seen an increased prevalence of MS in countries at high latitudes, where the sunlight is limited and where the populations have vitamin D deficiency and high melatonin levels. Although the functions and synthesis of vitamin D and melatonin are contrary to each other, both are involved in the immune system. While melatonin synthesis is affected by light, vitamin D deficiency may be involved in melatonin secretion. On the other hand, vitamin D deficiency reduces intestinal calcium absorption leading to gut stasis and subsequently increasing gut permeability. The latter allows gut microbiota to transfer more endotoxins such as lipopolysaccharides (LPS) into the blood. LPS stimulates the production of inflammatory cytokines within the CNS, especially the pineal gland. This review summarizes the current findings on the correlation between latitude, sunlight and vitamin $\mathrm{D}$, and details their effects on intestinal calcium absorption, gut microbiota and neuroinflammatory mediators in MS. We also propose a new mechanistic pathway for the initiation of MS.

Keywords: multiple sclerosis, latitude, sunlight, vitamin D, melatonin, gut microbiota

\section{INTRODUCTION}

Multiple sclerosis (MS) is an inflammatory demyelinating disease of the central nervous system (CNS) affecting over 2.5 million young adults worldwide; this condition develops when activated immune cells attack the CNS (1). Previous studies using advanced neuroimaging, neuroimmunological, and neuropathological technologies demonstrated that MS is not a single disease but rather a spectrum at disease (2). Symptoms of MS may differ greatly between patients and its progression depends on various factors affecting mainly the nerve processes. The exact mechanism responsible for this destructive disease is still unknown. Several immunological pathways have been suggested to be involved in MS owing to the use of the experimental autoimmune encephalomyelitis (EAE) animal model, the most widely used and best model for clinical MS (3). In the absence of a firm understanding of the mechanisms underlying MS, 
researchers have suggested a combination of risk factors that are involved in this disease; however, their specific contribution to MS pathogenesis is largely unknown. Among others, these risk factors include age, sex, family history, infections, race, climate, environment, and smoking (4).

Environmental factors, such as exposure to infectious agents, sunlight and vitamin $\mathrm{D}$ levels have long been considered as potent risk factors in people under 15 years of age (5). Both epidemiological and immunological data support the idea that some chronic bacterial infections may reside within the CNS and initiate pathological states $(6,7)$. On the other hand, high prevalence of MS has been reported in areas with short days and long night periods that may last 6-8 months per year (8). Moreover, vitamin D deficiency is commonplace in these regions of limited sunshine durations.

This survey critically reviews the literature in an attempt to clarify whether any connection exists between sunlight, vitamin $\mathrm{D}$, and bacterial infection toward causing MS and suggests a new mechanism by which MS may be triggered.

\section{LATITUDE, SUNLIGHT, AND VITAMIN D IN MULTIPLE SCLEROSIS}

About $85 \%$ of the world population lives at latitudes between the 40th parallels North and South, as a result, these individual are routinely exposed to sunlight (8). However, the remainder of the population (15\%) lives at higher latitudes in the northern half of the USA, Europe, Canada, and Russia or in the southern hemisphere in New Zealand, Tasmania and Patagonia. The individuals at these high latitudes receive relatively lower amounts of sunshine while they have the highest rate of MS. Indeed, the incidence of MS in these individuals ranges from 110 to 140 cases per 100,000 people, which is two-fold greater than the rate between the 40th parallels which has about 57 to 78 cases per 100,000 (9). The incidence of MS is also higher in colder climates (10).

Inadequate exposure to sunlight has been introduced as the main risk factor for vitamin D deficiency (11). It is well documented that short days and weak sunlight do not trigger vitamin $\mathrm{D}$ synthesis in the skin at latitudes above 40 degrees North $(10,12)$ where the population relies on dietary rather than light-synthetized vitamin D (13). Two forms of vitamin D are present: D2 and D3, ergocalciferol, and cholecalciferol, respectively. Vitamin D2 is produced by some plants in response to UV radiation whereas vitamin D3 is synthesized in the skin of humans and animals via the UV irradiation of 7-dehydrocholesterol to provitamin D3, the most biologically active form (14-16). Importantly, vitamin D is a major regulator of the immune system (17) and various immunological diseases, especially MS (18).

\footnotetext{
Abbreviations: CNS, central nervous system; MS, multiple sclerosis; LPS, lipopolysaccharides; EAE, experimental autoimmune encephalomyelitis; ipRGCs, intrinsically photosensitive retinal ganglion cells; RGCs, retinal ganglion cells; SCN, suprachiasmatic nucleus; BBB, blood brain barrier; SMCs, smooth muscle cells; TLR4, Toll like receptor 4; LBP, LPS-binding protein.
}

We have reviewed the literature related to MS prevalence and vitamin $\mathrm{D}$ levels in Sweden, a country that is mostly present above $60^{\circ}$ North latitude (12), where people experience long nights, especially during the winter. The prevalence of MS in 2011 was 189/100,000 individuals (19). Ultraviolet radiation in Sweden, particularly at northern latitudes, is too low to allow the synthesis of vitamin $\mathrm{D}$ during the winter months where the sun is above the horizon $(20,21)$. Concerning vitamin D levels in the Swedish population, several studies clearly reported vitamin D deficiency $(22,23)$. These observations are similar to those for New Zealand in the south hemisphere (24). Geographically, the prevalence of MS decreases by moving toward the equator (25), which further implicates sunlight and vitamin $\mathrm{D}$ as contributors to this serious disease (26).

\section{MELATONIN, VITAMIN D, AND MULTIPLE SCLEROSIS}

Melatonin, known as the chemical expression of darkness, is a sunlight dependent molecule released from pineal gland in response to darkness (27). Melatonin levels correlate with neuroimmunological diseases and are inversely related to the severity of MS and its relapse (28-32). These observations prompted researchers to investigate melatonin's effect on MS using experimental autoimmune encephalomyelitis (EAE) animal models. When tested, the severity of this condition was ameliorated using melatonin (33-35). We previously reported, however, that the action of melatonin in EAE rats may be age related (36). At the clinical level, MS patients administered melatonin as a sole treatment for 4 years recovered to 6.0 at the Expanded Disability Status Scale (EDSS), from an initial 8.0 level (32).

While several clinical studies investigated vitamin D-mediated functions in MS, the mechanisms by which vitamin D or melatonin functions relate to MS are not known. Previous studies clearly noted a reduction of vitamin D levels in MS patients, compared to healthy subjects; hence, hypovitaminosis $\mathrm{D}$ has been suggested to be a risk factor for MS (37). However, the evidence for a role of vitamin D as a treatment for MS is inconclusive and larger studies are needed (38). As a strategy to ameliorate the severity of MS, low-dose vitamin D supplementation did not show a significant effect on the EDSS score or relapse rate of MS patients (39). Conversely, some studies reported that increased vitamin $\mathrm{D}$ levels reduce the incidence and disease course of MS (40-42). A recent study showed an inverse correlation between changes in serum levels of vitamin D and melatonin. Indeed, the night secretion of melatonin was shown to be reduced after 3 months' administration of high dose vitamin D in IFN- $\beta$ treated MS patients. Moreover, there was a reduction in serum vitamin $\mathrm{D}$ levels when melatonin levels rose at night (43).

\section{VITAMIN D, MELATONIN, AND THE EYE}

Both vitamin $\mathrm{D}$ and melatonin are individually essential for cellular physiology; their rhythms are contrary to each other. Vitamin D is synthesized in the skin when it is exposed to ultra 
violet radiation from the sun whereas melatonin synthesis by the pineal gland occurs primarily at night. While vitamin $\mathrm{D}$ is present in certain foods, the bulk of it is obtained through exposure to sunlight. Conversely, the pineal gland produces melatonin primarily at night $(44,45)$, but it is also, like vitamin $\mathrm{D}$, consumed in the diet (46). It is well established that melatonin secretion from the pineal gland peaks near the middle of the dark phase and then declines slowly and gradually $(47,48)$. It is possible that increasing vitamin $\mathrm{D}$ levels during the day may act, in part, as a signal that suppresses melatonin generation (43).

In the mammalian retina, rod and cone photoreceptors, whose photopigments are rhodopsin and photopsin, are responsible for the image-forming vision. Newly identified photoreceptors in the inner retina named "intrinsically photosensitive retinal ganglion cells (ipRGCs)” are responsible for non-image-forming vision such as regulation of circadian rhythms and pupil size (49-52). These retinal ganglion cells (RGCs) are also involved in melatonin regulation where ipRGCs selectively express melanopsin, a novel opsin-like protein and a photopigment whose expression is restricted to $<2 \%$ of RGCs (53). Melanopsin regeneration is different from that of rhodopsin $(54,55)$. Melanopsin exists in equilibrium in two stable states under broadband light conditions and exhibits a peak spectral sensitivity in the blue wavelengths at $\sim 482 \mathrm{~nm}$. It is important to note that ipRGSc are involved in non-visual responses to light, especially blue light (56). The circadian rhythm of pineal melatonin is regulated by signals coming from suprachiasmatic nucleus (SCN) of the hypothalamus (57). ipRGC axons project to the SCN and it is this pathway that ultimately controls pineal melatonin production (58).

It is now known that exposure to blue light activates melanopsin and inhibits the SCN to synthesize and release melatonin (59-61). A recent study indicated that loss of visual axons and RGCs could be associated with vitamin D deficiency, consistent with the neuro-steroid effects of vitamin D in the CNS (62). While RGCs play a critical role in regulating melatonin production/release, the effect of vitamin D deficiency on RGCs could relate vitamin D deficiency with melatonin. This is a subject worthy of investigation. Immunologically, both hormones play a critical role in the blood brain barrier (BBB) integrity $(63,64)$.

\section{VITAMIN D AND INTESTINAL CALCIUM ABSORPTION}

Calcium is an abundant element in the human body and exhibits key roles in many physiological processes including blood clotting, hormone secretion, bone mineralization, nerve impulse transmission, and muscle contraction (65). While melatonin influences calcium absorption (66), vitamin D3 is the main hormone controlling intestinal calcium uptake (67). The importance of vitamin D deficiency in impairing calcium absorption from the intestine has been known for decades $(68,69)$. Several studies have shown, using vitamin D receptor (VDR) knockout mice, that vitamin $\mathrm{D}$ directly enhances intestinal calcium absorption (70, 71). In addition, it has been clearly documented that intestinal calcium absorption is reduced in vitamin $\mathrm{D}$ deficient animals and patients with low circulating vitamin D levels $(72,73)$.

Gastrointestinal motility involves a complex tightly coordinated series of contractions and relaxations of gastrointestinal smooth muscles, which are essential to maintain the orderly process of digestion. While most muscle cells use free calcium present in the cytosol for this process, gastrointestinal smooth muscle cells (SMCs) use calcium that has been imported from the extracellular fluid through special channels (74). Intestinal muscle cells need to increase and then reduce the concentration of calcium to initiate the contraction and relaxation of the intestinal muscles, respectively (75). This calcium variation is one of the main regulatory factors that affects intestinal motility. This observation led for simultaneous administration of vitamin $\mathrm{D}$ and calcium as a therapeutic strategy to stimulate normal intestinal motility in humans (76). In addition to the critical role of vitamin D3 in intestinal calcium absorption and intestinal motility, it may be involved in maintaining the integrity of the intestinal barrier and protecting it against mucosal injury (77).

\section{INTESTINAL CALCIUM ABSORPTION, GUT MICROBIOTA, AND MULTIPLE SCLEROSIS}

The reduction in intestinal calcium absorption leads to disruptions in intestinal motility and subsequently causes stasis of aboral movement (gut stasis) and gastroparesis in the long term (78). Gut stasis is a potentially deadly condition in which the digestive system slows down or stops completely whereas gastroparesis is a chronic disorder of delayed gastric emptying characterized by food remaining in the stomach for a longer time than normal (79). Gill etal. (80) reported for the first time a role of intestinal aboral movement in MS patients with intractable constipation. Two other studies in MS patients complaining of constipation or fecal incontinence reported that an efficient therapy for MS patients is gut focused behavioral treatment (biofeedback), especially for those with non-progressive limited disability $(81,82)$. In addition, a similar study in MS patients with constipation symptoms suggested a positive effect of abdominal massage on constipation symptoms and alleviation of MS severity (83).

Abnormalities of slow intestinal movement such as gut stasis, gastroparesis, and constipation seems to cause a rise in intestinal absorption including bacterial toxins. In support of this hypothesis, several previous studies clearly showed that gut stasis leads to elevated gut permeability and bacterial translocation (75, 84-87). This ultimately releases toxic mediators which further increases gut permeability (88-91). Conversely, alterations in the gut microbiota may to be involved in some neurological and autoimmune conditions (92), especially MS (93). For instance, it has been reported that patients in the active or remission phases of relapsing-remitting MS (RRMS) have gut microbial dysbiosis (94). Another similar study in children $(\leq 18$ years old within 2 years of MS) showed increased levels of gut gram-negative bacteria that could be associated with neurodegeneration (95). Moreover, gut bacteria can also affect the integrity of $\mathrm{BBB}$, which is critical in MS (96). 
TABLE 1 | Clinical and review studies.

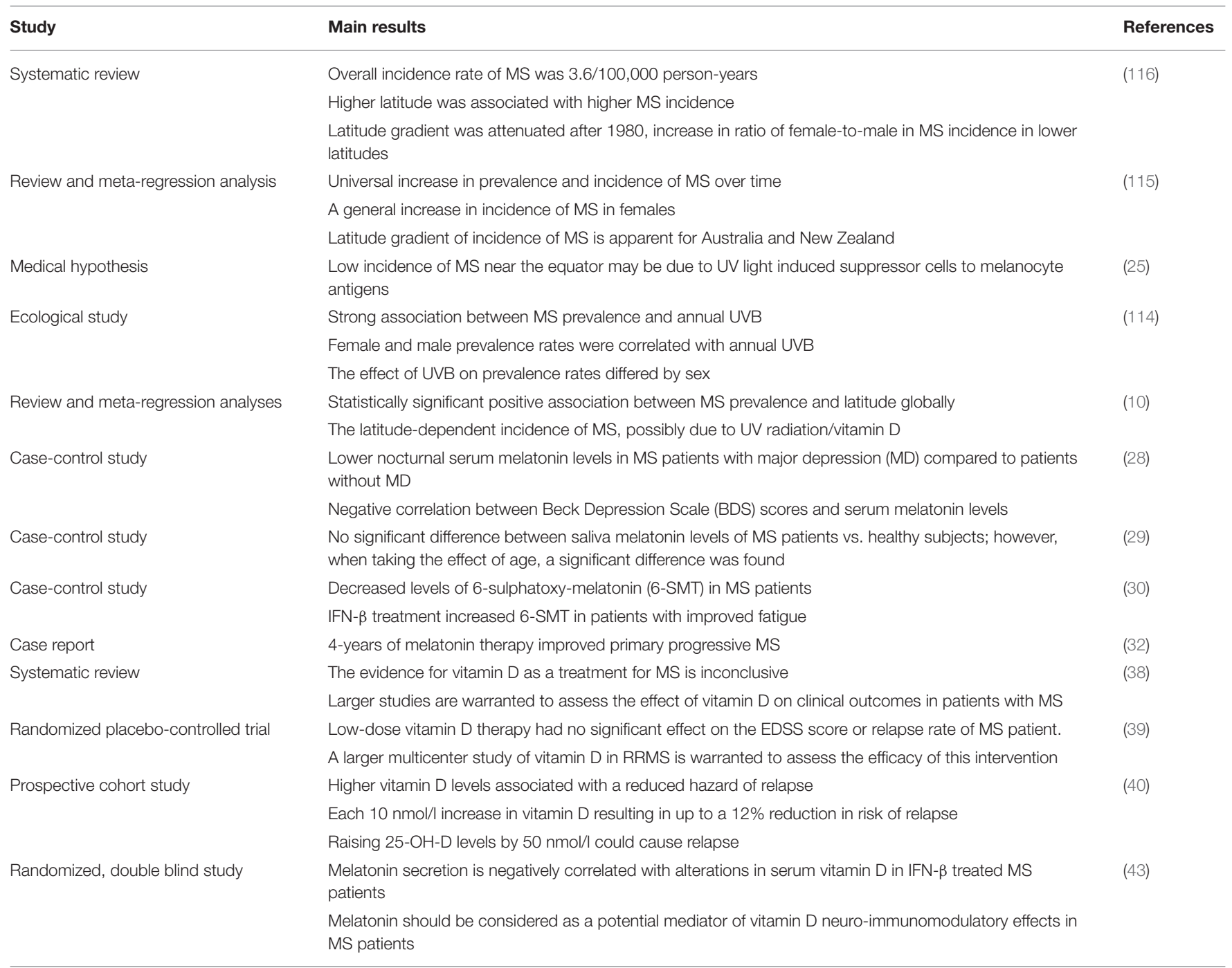

TABLE 2 | Experimental studies on EAE.

\section{Main result}

References

Melatonin therapy reduced the clinical severity of EAE

Melatonin reduced immune cell infiltration into the spinal cord of EAE

Melatonin protects against EAE by controlling peripheral and central $T$ effector/regulatory responses

Melatonin modulates adaptive immunity centrally and peripherally in EAE mice

Melatonin suppresses the expression of IFN- $\gamma$, IL-17, IL-6, and CCL20 in the CNS of EAE and inhibits antigen-specific T cell proliferation

A relationship exists between age and the development of EAE

Melatonin in young EAE rats exacerbated disease severity

Vitamin D therapy suppresses the severity of clinical scores and reduces IL-6 and IL-17

Dietary calcium and vitamin $\mathrm{D}$ are both involved in the prevention of symptomatic EAE

Vitamin D could reduce the severity of disease only when accompanied by elevated serum calcium

Exposure to UVB reduced EAE incidence by $74 \%$

Exposure to UVB increased the conversation of skin trans-urocanic acid to cis-urocanic acid

Enhanced skin cis-urocanic acid levels independent of UVB was unable to reduce EAE

Vitamin $D$ therapy prevents blood brain barrier disruption caused by relapse-remitting MS and secondary progressive MS 


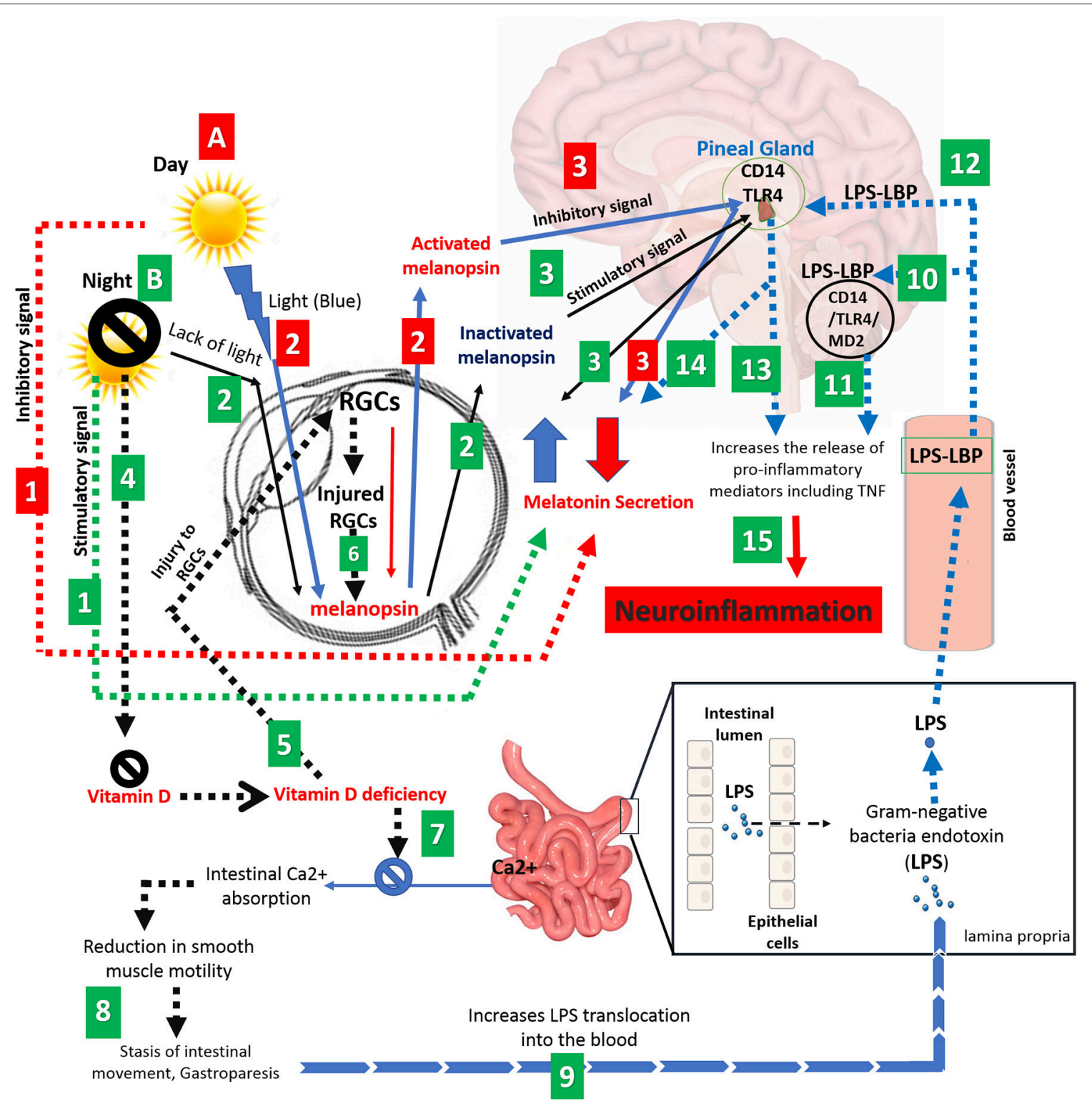

FIGURE 1 | Schematic representation correlating various factors such as light, eye, melanopsin, pineal gland, vitamin D, intestinal calcium, and gut microbiota to neuroinflammation and MS. (A) Adequate exposure to sunlight; (1) Long days and adequate exposure to sunlight suppresses the melatonin secretion and (2) leads to activation of melanopsin, generated by RGCs. (3) Activated melanopsin by sunlight sends an inhibitory signal to pineal gland to decreases the melatonin secretion. (Red numbered rectangle). (B) Inadequate exposure to sunlight; (1) Long nights and/or inadequate exposure to sunlight increase the level of melatonin (black arrow), (2) causes melanopsin inactivation and. (3) Promotion in level of inactivated melanopsin by darkness leads to sending a stimulatory signal to pineal gland to cause a further increase in melatonin levels. (4) On the other hand, darkness leads to Vitamin D deficiency. (5) Vitamin D deficiency causes injury to RGCs, (6) reducing melanopsin secretion (dashed black arrow). (7) Vitamin D deficiency also causes disruption in intestinal calcium absorption, which (8) leads to a reduction in smooth muscles of the intestine and subsequently gut stasis. (9) The latter increases gut permeability and LPS translocation toward the CNS. (10) LPS activates CD14/TLR4/MD2 complex which (11) increases the proinflammatory mediators in the brain such as TNF- $\alpha$. (12) CD14 and TLR4 receptors in the pineal gland respond to LPS by (13) TNF secretion and (14) suppression of melatonin synthesis. (15) Eventually, secreted proinflammatory mediators and activated NF-kB pathway leads to neuroinflammation and possible demyelination at the long term. (Green numbered rectangle).

\section{GUT MICROBIOTA, CD14, TOLL LIKE RECEPTOR 4 (TLR4), AND MELATONIN}

The intestine of animals and humans contain gut microbiota which produce endotoxic compounds including lipopolysaccharides (LPS), a component of gram-negative bacterial outer membrane $(97,98)$. The rise in LPS levels in gut microbiota increases the blood LPS through gut inflammation (99). LPS is recognized by LPS-binding protein (LBP) in the serum which brings the LPS to the surface of various cells such 
as macrophages and endothelial cells to form a complex with CD14, a receptor molecule for LPS. CD14 splits LPS aggregates into monomeric molecules and facilitates the transfer of LPS to TLR4/MD2 complex. MD2 is a secreted glycoprotein that functions as an indispensable extracellular adaptor molecule for LPS-signaling events. Activation of TLR4/MD2 complex upon binding to LPS leads to LPS-mediated NFkB activation and production of pro-inflammatory cytokines such as tumor necrosis factor-alpha (TNF- $\alpha)$ (100-107).

The role of the pineal gland/melatonin in response to LPS is controversial. Melatonin was shown to inhibit the LPS-CD14TLR4 signaling pathway in bovine mammary epithelial cells and decreased LPS-induced expression of pro-inflammatory cytokines such as TNF- $\alpha$, IL- $1 \beta$, and IL-6 (108). In contrast, pineal cells possess both TLR4 and CD14 that bind to LPS and activate NF- $k$ B pathway by increasing the level of TNF, which subsequently suppresses melatonin synthesis (109). Since CD14 is the major cell surface receptor for LPS on monocytes/macrophages (110), the authors established that melatonin increased the secretion of IL-1 in vitro and in vivo $(111,112)$ and TNF- $\alpha$ and IL-6 in vivo $(112,113)$. These data support the hypothesis that LPS produced by gut microbiota causes neuroinflammation that in turn induces higher levels of LPS stimulating the pineal gland to activate the NF-kB pathway and to produce TNF- $\alpha$ while suppressing melatonin synthesis.

\section{UV IRRITATION, VITAMIN D, GASTROPARESIS}

Higher latitude has been associated with higher MS incidence and lower UV exposure. In support of the role of latitude in MS susceptibility, a recent study suggested that regional UVB radiation affects MS prevalence which supports the hypothesis that exposure to sunlight can influence MS risk (114). The latter study highlighted the potential role of gender-specific effects of UVB, a suggestion that is also proposed by meta-regression analyses (115) and by incidence studies of MS (116). In fact, an experimental study demonstrated that UVB therapy can suppress EAE; however, its effect does not proceed via the production of vitamin $\mathrm{D}$ (117). On the other hand, although vitamin $\mathrm{D}$ levels are low in MS patients, evidence that vitamin D prescription can reduce the incidence of MS has not been obtained yet (118-120). Importantly, vitamin $\mathrm{D}$ could reduce the severity of disease only when it was accompanied by elevated serum calcium (121).

To investigate the involvement of UV in MS progression, Irving and colleagues demonstrated that EAE incidence was reduced by $74 \%$ following UVB radiation (122). Since UVB photons enter the skin to produce vitamin D3 during exposure to sunlight (123), Irving and colleagues showed that UVB therapy in EAE caused an increase in the levels of skin cis-urocanic acid levels, an intermediate in the catabolism of 1-histidine. Moreover, they also observed that enhancement of skin cisurocanic acid levels independent of UVB cannot affect the disease onset or progression (122). On the other hand, it has been demonstrated that cis-urocanic acid causes a reduction in the severity of colitis, a chronic inflammatory condition of the gut (124). In addition, colitis was shown to delay gastric emptying and leads to colitis-induced gastroparesis in animal models (124). In accordance, it has been reported that women are more susceptible to gastroparesis than men (125), while the incidence of MS is about 3-fold higher in women than in men. We therefore suggest that gastroparesis could be one of the main factors involved in triggering MS.

The summarized results and highlights about the clinical and experimental studies on MS patients and EAE model have been demonstrated in Table 1 and Table 2, respectively.

\section{CONCLUSION}

We suggest a new pathway that lead to neuroinflammation and MS by including different factors such as latitude, sunlight, vitamin D, melanopsin, intestinal calcium, pineal gland, gut stasis, gut endotoxins (LPS), and CD14/TLR4 (Figure 1). While the prevalence of MS is dramatically higher at latitudes above 40 degrees North and South, populations in these areas receive limited sunlight that may lead to a longer increase in melatonin synthesis and release. Since the functions and synthesis of melatonin and vitamin D are contrary to each other, we believe that therapy using these hormones would not be an effective strategy for the treatment of MS patients with low melatonin levels or vitamin D deficiency. We suggest that a balance should exist between these two hormones. In dark periods, melanopsin in the RGCs is inactivate allowing the pineal gland to synthesize melatonin; however, vitamin D levels decrease dramatically and patients face vitamin D deficiency with long term sunlight deprivation. This low level of vitamin $\mathrm{D}$ causes RGC injury which contain melanopsin and also reduces intestinal calcium absorption, essential for intestinal smooth muscle contraction. Vitamin D deficiency and reduction of calcium absorption leads to gut stasis and subsequently increases the gut permeability allowing gut microbiota to transfer more endotoxins such as LPS into the blood. Translocated LPS migrates to the brain and triggers the production of proinflammatory mediators through CD14/TLR4/MD2 complex. CD14 and TLR4 receptors within the pineal gland respond to LPS with induced TNF secretion while melatonin synthesis is suppressed causing neuroinflammation and contributing to the development of MS in the long term. Further experimental and clinical studies are needed to unravel the mechanisms of MS induction.

\section{AUTHOR CONTRIBUTIONS}

MG, RR, KZ, and NF: concept and design of the review, drafting the manuscript and figures. All authors have read, critically revised, and approved the final manuscript before submission. KZ and NF have equal contribution and are co-last and corresponding authors. 


\section{REFERENCES}

1. Haase CG, Tinnefeld M, Faustmann PM. The influence of immunomodulation on psycho-neuroimmunological functions in benign multiple sclerosis. Neuroimmunomodulation (2004) 11:365-72. doi: 10.1159/000080146

2. Golan D, Staun-Ram E, Miller A. Shifting paradigms in multiple sclerosis: from disease-specific, through population-specific toward patient-specific. Curr Opin Neurol. (2016) 29:354-61. doi: 10.1097/WCO.0000000000000324

3. Loma I, Heyman R. Multiple sclerosis: pathogenesis and treatment. Curr Neuropharmacol. (2011) 9:409-16. doi: 10.2174/157015911796557911

4. Giulio D, Julia MM, Sreeram VR. Multiple sclerosis: risk factors and their interactions. CNS Neurol Disord Drug Targets (2012) 11:545-55. doi: 10.2174/187152712801661266

5. Milo R, Kahana E. Multiple sclerosis: geoepidemiology, genetics and the environment. Autoimmun Rev. (2010) 9:A387-94. doi: 10.1016/j.autrev.2009.11.010

6. Estanislao LB, Pachner AR. Spirochetal infection of the nervous system. Neurol Clin. (1999) 17:783-800. doi: 10.1016/S0733-8619(05)70166-3

7. Pawate S, Sriram S. The role of infections in the pathogenesis and course of multiple sclerosis. Ann Indian Acad Neurol. (2010) 13:80-6. doi: 10.4103/0972-2327.64622

8. Pierrot-Deseilligny C, Souberbielle JC. Is hypovitaminosis D one of the environmental risk factors for multiple sclerosis? Brain (2010) 133:1869-88. doi: 10.1093/brain/awq147

9. Goodin DS. The causal cascade to multiple sclerosis: a model for Ms pathogenesis. PLoS ONE (2009) 4:E4565. doi: 10.1371/journal.pone.0004565

10. Simpson S, Blizzard L, Otahal P, Van Der Mei I, Taylor B. Latitude is significantly associated with the prevalence of multiple sclerosis: a meta-analysis. J Neurol Neurosurg Psychiatry (2011) 82:1132. doi: 10.1136/jnnp.2011.240432

11. Holick MF, Binkley NC, Bischoff-Ferrari HA, Gordon CM, Hanley DA, Heaney RP, et al. Evaluation, treatment, and prevention of vitamin D deficiency: an endocrine society clinical practice guideline. J Clin Endocrinol Metab. (2011) 96:1911-30. doi: 10.1210/jc.2011-0385

12. Spiro A, Buttriss JL. Vitamin D: an overview of vitamin D status and intake in Europe. Nutr Bull/BNF (2014) 39:322-50. doi: 10.1111/nbu.12108

13. O'connor A, Benelam B. An update on UK vitamin D intakes and status, and issues for food fortification and supplementation. Nutr Bull. (2011) 36:390-6. doi: 10.1111/j.1467-3010.2011.01918.x

14. Plum LA, Deluca HF. Vitamin D, disease and therapeutic opportunities. Nat Rev Drug Discov. (2010) 9:941-55. doi: 10.1038/nrd3318

15. Tripkovic L, Lambert H, Hart K, Smith CP, Bucca G, Penson S, et al. Comparison Of vitamin $\mathrm{D}(2)$ and vitamin $\mathrm{D}(3)$ supplementation in raising serum 25-hydroxyvitamin D status: a systematic review and meta-analysis. Am J Clin Nutr. (2012) 95:1357-64. doi: 10.3945/ajcn.111.031070

16. Veldurthy V, Wei R, Oz L, Dhawan P, Jeon YH, Christakos S. Vitamin D, calcium homeostasis and aging. Bone Res. (2016) 4:16041. doi: 10.1038/boneres.2016.41

17. Aranow C. Vitamin D and the immune system. J Invest Med. (2011) 59:8816. doi: 10.2310/JIM.0b013e31821b8755

18. Takahashi S, Maeda T, Sano Y, Nishihara H, Takeshita Y, Shimizu $\mathrm{F}$, et al. Active form of vitamin D directly protects the blood-brain barrier in multiple sclerosis. Clin Exp Neuroimmunol. (2017) 8:244-54. doi: $10.1111 /$ cen 3.12398

19. Ahlgren C, Odén A, Lycke J. High nationwide prevalence of multiple sclerosis in Sweden. Multiple Scler J. (2011) 17:901-8. doi: $10.1177 / 1352458511403794$

20. Klingberg E, Oleröd G, Konar J, Petzold M, Hammarsten O. Seasonal variations in serum 25-hydroxy vitamin D levels in a Swedish cohort. Endocrine (2015) 49:800-8. doi: 10.1007/s12020-015-0548-3

21. Engelsen O, Brustad M, Aksnes L, Lund E. Daily duration of vitamin D synthesis in human skin with relation to latitude, total ozone, altitude, ground cover, aerosols and cloud thickness. Photochem Photobiol. (2005) 81:1287-90. doi: 10.1562/2004-11-19-RN-375

22. Samefors M, Ostgren CJ, Molstad S, Lannering C, Midlov P, Tengblad A. Vitamin D deficiency in elderly people in Swedish nursing homes is associated with increased mortality. Eur J Endocrinol. (2014) 170:667-75. doi: 10.1530/EJE-13-0855

23. Andersson Å, Björk A, Kristiansson P, Johansson G. Vitamin D intake and status in immigrant and native Swedish women: a study at a primary health care centre located at $60^{\circ} \mathrm{N}$ in Sweden. Food Nutr Res. (2013) 57: 20089. doi: 10.3402/Fnr.V57i0.20089

24. Alla S, Pearson J, Debernard L, Miller D, Mason D. The increasing prevalence of multiple sclerosis in New Zealand. Neuroepidemiology (2014) 42:154-60. doi: 10.1159/000358174

25. Sharpe RJ. The low incidence of multiple sclerosis in areas near the equator may be due to ultraviolet light induced suppressor cells to melanocyte antigens. Med Hypotheses (1986) 19:319-23. doi: 10.1016/0306-9877(86)90104-0

26. Harandi AA, Harandi AA, Pakdaman H, Sahraian MA. Vitamin D and multiple sclerosis. Iran J Neurol. (2014) 13:1-6.

27. Reiter RJ. Melatonin: the chemical expression of darkness. Mol Cell Endocrinol. (1991) 79:C153-8. doi: 10.1016/0303-7207(91)90087-9

28. Akpinar Z, Tokgoz S, Gokbel H, Okudan N, Uguz F, Yilmaz G. The association of nocturnal serum melatonin levels with major depression in patients with acute multiple sclerosis. Psychiatry Res. (2008) 161:253-7. doi: 10.1016/j.psychres.2007.11.022

29. Ghorbani A, Salari M, Shaygannejad V, Norouzi R. The role of melatonin in the pathogenesis of multiple sclerosis: a case-control study. Int J Prevent Med. (2013) 4:S180-4.

30. Melamud L, Golan D, Luboshitzky R, Lavi I, Miller A. Melatonin dysregulation, sleep disturbances and fatigue in multiple sclerosis. J Neurol Sci. (2012) 314:37-40. doi: 10.1016/j.jns.2011.11.003

31. Sandyk R. Multiple sclerosis: the role of puberty and the pineal gland in its pathogenesis. Int $J$ Neurosci. (1993) 68:209-25. doi: 10.3109/00207459308994277

32. Lopez-Gonzalez A, Alvarez-Sanchez N, Lardone PJ, Cruz-Chamorro I, Martinez-Lopez A, Guerrero JM, et al. Melatonin treatment improves primary progressive multiple sclerosis: a case report. J Pineal Res. (2015) 58:173-7. doi: 10.1111/jpi.12203

33. Kang JC, Ahn M, Kim YS, Moon C, Lee Y, Wie MB, et al. Melatonin ameliorates autoimmune encephalomyelitis through suppression of intercellular adhesion molecule-1. J Vet Sci. (2001) 2:85-9.

34. Alvarez-Sanchez N, Cruz-Chamorro I, Lopez-Gonzalez A, Utrilla JC, Fernandez-Santos JM, Martinez-Lopez A, et al. Melatonin controls experimental autoimmune encephalomyelitis by altering the $\mathrm{T}$ effector/regulatory balance. Brain Behav Immun. (2015) 50:101-14. doi: 10.1016/j.bbi.2015.06.021

35. Chen SJ, Huang SH, Chen JW, Wang KC, Yang YR, Liu PF, et al. Melatonin enhances interleukin-10 expression and suppresses chemotaxis to inhibit inflammation in situ and reduce the severity of experimental autoimmune encephalomyelitis. Int Immunopharmacol. (2016) 31:169-77. doi: 10.1016/j.intimp.2015.12.020

36. Ghareghani M, Dokoohaki S, Ghanbari A, Farhadi N, Zibara K, Khodadoust S, et al. Melatonin exacerbates acute experimental autoimmune encephalomyelitis by enhancing the serum levels of lactate: a potential biomarker of multiple sclerosis progression. Clin Exp Pharmacol Physiol. (2017) 44:52-61. doi: 10.1111/1440-1681.12678

37. Dudani SJ, Kalhan S, Sharma SP. Vitamin D and multiple sclerosis: potential pathophysiological role and clinical implications. Int J Appl Basic Med Res. (2011) 1:71-4. doi: 10.4103/2229-516X.91146

38. Pozuelo-Moyano B, Benito-Leon J, Mitchell AJ, Hernandez-Gallego J. A systematic review of randomized, double-blind, placebo-controlled trials examining the clinical efficacy of vitamin $\mathrm{D}$ in multiple sclerosis. Neuroepidemiology (2013) 40:147-53. doi: 10.1159/0003 45122

39. Shaygannejad V, Janghorbani M, Ashtari F, Dehghan H. Effects of adjunct low-dose vitamin D on relapsing-remitting multiple sclerosis progression: preliminary findings of a randomized placebo-controlled trial. Multiple Scler Int. (2012) 2012:452541. doi: 10.1155/2012/452541

40. Simpson S Jr, Taylor B, Blizzard L, Ponsonby AL, Pittas F, Tremlett H, et al. Higher 25-hydroxyvitamin D is associated with lower relapse risk in multiple sclerosis. Ann Neurol. (2010) 68:193-203. doi: 10.1002/ana.22043 
41. Munger KL, Ascherio A. Prevention and treatment of MS: studying the effects of vitamin D. Multiple Scler. (2011) 17:1405-11. doi: $10.1177 / 1352458511425366$

42. Holmøy T, Torkildsen $\varnothing$, Myhr KM, Løken-Amsrud KI. Vitamin D supplementation and monitoring in multiple sclerosis: who, when and wherefore. Acta Neurol Scand. (2012) 126:63-9. doi: 10.1111/ane.12028

43. Golan D, Staun-Ram E, Glass-Marmor L, Lavi I, Rozenberg O, Dishon S, et al. The influence of vitamin D supplementation on melatonin status in patients with multiple sclerosis. Brain Behav Immun. (2013) 32:180-5. doi: 10.1016/j.bbi.2013.04.010

44. Champney Thomas H, Holtorf AP, Steger RW, Reiter RJ. Concurrent determination of enzymatic activities and substrate concentrations in the melatonin synthetic pathway within the same rat pineal gland. $J$ Neurosci Res. (1984) 11:59-66. doi: 10.1002/jnr.490110107

45. Brzezinski A. Melatonin in humans. N Engl J Med. (1997) 336:186-95. doi: 10.1056/NEJM199701163360306

46. Reiter RJ, Tan DX, Burkhardt S, Manchester LC. Melatonin in plants. Nutr Rev. (2001) 59:286-90. doi: 10.1111/j.1753-4887.2001.tb07018.x

47. Reiter RJ. The melatonin rhythm: both a clock and a calendar. Experientia (1993) 49:654-64. doi: 10.1007/BF01923947

48. Malpaux B, Migaud M, Tricoire H, Chemineau P. Biology of mammalian photoperiodism and the critical role of the pineal gland and melatonin. J Biol Rhythms (2001) 16:336-47. doi: 10.1177/074873001129002051

49. Yamazaki S, Goto M, Menaker M. No evidence for extraocular photoreceptors in the circadian system of the Syrian hamster. J Biol Rhythms (1999) 14:197-201. doi: 10.1177/074873099129000605

50. Ruby NF, Brennan TJ, Xie X, Cao V, Franken P, Heller HC, et al. Role of melanopsin in circadian responses to light. Science (2002) 298:2211-3. doi: 10.1126/science.1076701

51. Gamlin PD, Mcdougal DH, Pokorny J, Smith VC, Yau KW, Dacey DM. Human and macaque pupil responses driven by melanopsincontaining retinal ganglion cells. Vision Res. (2007) 47:946-54. doi: 10.1016/j.visres.2006.12.015

52. Paul KN, Saafir TB, Tosini G. The role of retinal photoreceptors in the regulation of circadian rhythms. Rev Endocr Metab Disord. (2009) 10:271-8. doi: 10.1007/s11154-009-9120-x

53. Hattar S, Liao HW, Takao M, Berson DM, Yau KW. Melanopsincontaining retinal ganglion cells: architecture, projections, and intrinsic photosensitivity. Science (2002) 295:1065-70. doi: 10.1126/science.1069609

54. Melyan Z, Tarttelin EE, Bellingham J, Lucas RJ, Hankins MW. Addition of human melanopsin renders mammalian cells photoresponsive. Nature (2005) 433:741-5. doi: 10.1038/nature03344

55. Mure LS, Rieux C, Hattar S, Cooper HM. Melanopsin-dependent nonvisual responses: evidence for photopigment bistability in vivo. J Biol Rhythms (2007) 22:411-24. doi: 10.1177/0748730407306043

56. Provencio I. Circadian Photoreception A2 - Dartt, Darlene A. Encyclopedia of the Eye. Oxford: Academic Press (2010).

57. Reppert SM, Weaver DR, Rivkees SA, Stopa EG. Putative melatonin receptors in a human biological clock. Science (1988) 242:78-81. doi: $10.1126 /$ science. 2845576

58. Gooley JJ, Lu J, Fischer D, Saper CB. A broad role for melanopsin in nonvisual photoreception. J Neurosci. (2003) 23:7093-106. doi: 10.1523/JNEUROSCI.23-18-07093.2003

59. Brainard GC, Hanifin JP, Greeson JM, Byrne B, Glickman G, Gerner E, et al. Action spectrum for melatonin regulation in humans: evidence for a novel circadian photoreceptor. J Neurosci. (2001) 21:6405-12. doi: 10.1523/JNEUROSCI.21-16-06405.2001

60. Mcdougal DH, Gamlin PD. The influence of intrinsically-photosensitive retinal ganglion cells on the spectral sensitivity and response dynamics of the human pupillary light reflex. Vision Res. (2010) 50:72-87. doi: 10.1016/j.visres.2009.10.012

61. Maynard ML, Zele AJ, Feigl B. Melanopsin-mediated post-illumination pupil response in early age-related macular degeneration. Invest Ophthalmol Visual Sci. (2015) 56:6906-13. doi: 10.1167/iovs.15-17357

62. Annweiler C, Beauchet O, Bartha R, Graffe A, Milea D, Montero-Odasso M. Association between serum 25-hydroxyvitamin D concentration and optic chiasm volume. J Am Geriatr Soc. (2013) 61:1026-8. doi: 10.1111/jgs.12249
63. Suzumura A. Effect of vitamin D on blood-brain barrier function in multiple sclerosis. Clin Exp Neuroimmunol. (2017) 8:180. doi: 10.1111/cen3.12410

64. Alluri H, Wilson RL, Anasooya Shaji C, Wiggins-Dohlvik K, Patel S, Liu $\mathrm{Y}$, et al. Melatonin preserves blood-brain barrier integrity and permeability via matrix metalloproteinase-9 inhibition. PLoS ONE (2016) 11:E0154427. doi: 10.1371/journal.pone.0154427

65. Peacock M. Calcium metabolism in health and disease. Clin J Am Soc Nephrol. (2010) 5(Suppl. 1):S23-30. doi: 10.2215/CJN.05910809

66. Sjoblom M, Safsten B, Flemstrom G. Melatonin-induced calcium signaling in clusters of human and rat duodenal enterocytes. Am J Physiol Gastrointest Liver Physiol. (2003) 284:G1034-44. doi: 10.1152/ajpgi.00500.2002

67. Christakos S. Recent advances in our understanding of 1,25dihydroxyvitamin $\mathrm{D}(3)$ regulation of intestinal calcium absorption. Arch Biochem Biophys. (2012) 523:73-6. doi: 10.1016/j.abb.2011.12.020

68. Devine A, Wilson SG, Dick IM, Prince RL. Effects of vitamin D metabolites on intestinal calcium absorption and bone turnover in elderly women. Am J Clin Nutr. (2002) 75:283-8. doi: 10.1093/ajcn/75.2.283

69. Fraser DR. Regulation of the metabolism of vitamin D. Physiol Rev. (1980) 60:551-613. doi: 10.1152/physrev.1980.60.2.551

70. Li YC, Pirro AE, Amling M, Delling G, Baron R, Bronson R, et al. Targeted ablation of the vitamin D receptor: an animal model of vitamin D-dependent rickets type II with alopecia. Proc Natl Acad Sci USA. (1997) 94:9831-5. doi: 10.1073/pnas.94.18.9831

71. Yoshizawa T, Handa Y, Uematsu Y, Takeda S, Sekine K, Yoshihara Y, et al. Mice lacking the vitamin D receptor exhibit impaired bone formation, uterine hypoplasia and growth retardation after weaning. Nat Genet. (1997) 16:391-6. doi: 10.1038/ng0897-391

72. Pansu D, Bellaton C, Roche C, Bronner F. Duodenal and ileal calcium absorption in the rat and effects of vitamin D. Am J Physiol. (1983) 244:G695700 .

73. Sheikh MS, Ramirez A, Emmett M, Santa Ana C, Schiller LR, Fordtran JS. Role of vitamin D-dependent and vitamin D-independent mechanisms in absorption of food calcium. J Clin Invest. (1988) 81:126-32. doi: 10.1172/JCI113283

74. Karaki H, Weiss GB. Calcium channels in smooth muscle. Gastroenterology (1984) 87:960-70.

75. Somlyo AP, Somlyo AV. Signal transduction and regulation in smooth muscle. Nature (1994) 372:231. doi: 10.1038/372231a0

76. Giraldi G, Fioravanti A, De Luca D’alessandro E, Palmery M, Martinoli L. Investigation of the effects of vitamin $\mathrm{D}$ and calcium on intestinal motility: in vitro tests and implications for clinical treatment. Acta Pharm (2015) 65:343-9. doi: 10.1515/acph-2015-0023

77. Kong J, Zhang Z, Musch MW, Ning G, Sun J, Hart J, et al. Novel role of the vitamin $\mathrm{D}$ receptor in maintaining the integrity of the intestinal mucosal barrier. Am J Physiol Gastrointest Liver Physiol. (2008) 294:G208-16. doi: 10.1152/ajpgi.00398.2007

78. Koenig J, Cote N. Equine gastrointestinal motility-ileus and pharmacological modification. Can Veter J. (2006) 47:551-9.

79. Parkman HP, Hasler WL, Fisher RS. American gastroenterological association technical review on the diagnosis and treatment of gastroparesis. Gastroenterology (2004) 127:1592-622. doi: 10.1053/j.gastro.2004.09.055

80. Gill KP, Chia YW, Henry MM, Shorvon PJ. Defecography in multiple sclerosis patients with severe constipation. Radiology (1994) 191:553-6. doi: 10.1148/radiology.191.2.8153339

81. Wiesel PH, Norton C, Roy AJ, Storrie JB, Bowers J, Kamm MA. Gut focused behavioural treatment (Biofeedback) for constipation and faecal incontinence in multiple sclerosis. J Neurol Neurosurg Psychiatry (2000) 69:240-3. doi: 10.1136/jnnp.69.2.240

82. Enck P, Van Der Voort I, Klosterhalfen S. Biofeedback therapy in fecal incontinence and constipation. Neurogastroenterol Motility (2009) 21:113341. doi: 10.1111/j.1365-2982.2009.01345.x

83. Mcclurg D, Hagen S, Hawkins S, Lowe-Strong A. Abdominal massage for the alleviation of constipation symptoms in people with multiple sclerosis: a randomized controlled feasibility study. Multiple Scler J. (2010) 17:223-33. doi: 10.1177/1352458510384899

84. Yacyshyn B, Meddings J, Sadowski D, Bowen-Yacyshyn MB. Multiple sclerosis patients have peripheral blood $\mathrm{Cd} 45 \mathrm{ro}+\mathrm{B}$ cells and 
increased intestinal permeability. Dig Dis Sci. (1996) 41:2493-8. doi: 10.1007/BF02100148

85. Nathens AB, Marshall JC. Sepsis, sirs, and mods: what's in a name? World J Surg (1996) 20:386-91.

86. Nieuwenhuijzen GA, Goris RJA. The gut: the "motor" of multiple organ dysfunction syndrome? Curr Opin Critic Care (1999) 5:126.

87. Hierholzer C, Kalff JC, Chakraborty A, Watkins SC, Billiar TR, Bauer AJ, et al. Impaired gut contractility following hemorrhagic shock is accompanied by Il-6 and G-Csf production and neutrophil infiltration. Digest Dis Sci (2001) 46:230-41. doi: 10.1023/A:1005524021552

88. Chieveley-Williams S, Hamilton-Davies C. The role of the gut in major surgical postoperative morbidity. Int Anesthesiol Clin. (1998) 37:81-110. doi: 10.1097/00004311-199903720-00006

89. Overhaus M, Tögel S, Pezzone MA, Bauer AJ. Mechanisms of polymicrobial sepsis-induced ileus. Am J Physiol-Gastrointestinal Liver Physiol. (2004) 287:G685-94. doi: 10.1152/ajpgi.00359.2003

90. Swank GM, Deitch EA. Role of the gut in multiple organ failure: bacterial translocation and permeability changes. World J Surg. (1996) 20:411-7. doi: 10.1007/s002689900065

91. Zheyu C, Qinghui Q, Lunan Y. Roles of calcium and Ip3 in impaired colon contractility of rats following multiple organ dysfunction syndrome. Braz J Med Biol Res. (2007) 40:1389-97. doi: 10.1590/S0100-879X2006005000147

92. Wang Y, Kasper LH. The role of microbiome in central nervous system disorders. Brain Behav Immun. (2014) 38:1-12. doi: 10.1016/j.bbi.2013.12.015

93. Wolfson C, Talbot P. Bacterial infection as a cause of multiple sclerosis. Lancet (2002) 360:352-3. doi: 10.1016/S0140-6736(02)09 603-4

94. Chen J, Chia N, Kalari KR, Yao JZ, Novotna M, Soldan MMP, et al. Multiple sclerosis patients have a distinct gut microbiota compared to healthy controls. Sci Rep. (2016a) 6:28484. doi: 10.1038/srep 28484

95. Tremlett H, Fadrosh DW, Faruqi AA, Zhu F, Hart J, Roalstad S, et al. Gut microbiota in early pediatric multiple sclerosis: a case-control study. Eur J Neurol. (2016) 23:1308-21. doi: 10.1111/ene.13026

96. Braniste V, Al-Asmakh M, Kowal C, Anuar F, Abbaspour A, Tóth M, et al. The gut microbiota influences blood-brain barrier permeability in mice. Sci Trans Med. (2014) 6:263ra158. doi: 10.1126/scitranslmed.30 09759

97. Poltorak A, He X, Smirnova I, Liu MY, Van Huffel C, Du X, et al. Defective LPS signaling in $\mathrm{C} 3 \mathrm{H} / \mathrm{HEJ}$ and $\mathrm{C} 57 \mathrm{bl} / 10$ sccr mice: mutations in Tlr4 gene. Science (1998) 282:2085-8. doi: 10.1126/science.282.5396.2085

98. Harmsen HJ, De Goffau MC. The human gut microbiota. Adv Exp Med Biol. (2016) 902:95-108. doi: 10.1007/978-3-319-31248-4_7

99. Jiang T, Gao X, Wu C, Tian F, Lei Q, Bi J, et al. Apple-derived pectin modulates gut microbiota, improves gut barrier function, and attenuates metabolic endotoxemia in rats with diet-induced obesity. Nutrients (2016) 8:126. doi: $10.3390 /$ nu8030126

100. Schumann RR, Leong SR, Flaggs GW, Gray PW, Wright SD, Mathison JC, et al. Structure and function of lipopolysaccharide binding protein. Science (1990) 249:1429-31. doi: 10.1126/science.2402637

101. Dunzendorfer S, Lee HK, Soldau K, Tobias PS. Tlr4 is the signaling but not the lipopolysaccharide uptake receptor. J Immunol. (2004) 173:1166-70. doi: 10.4049/jimmunol.173.2.1166

102. Da Silva Correia J, Soldau K, Christen U, Tobias PS, Ulevitch RJ. Lipopolysaccharide is in close proximity to each of the proteins in its membrane receptor complex. Transfer from Cd14 to Tlr4 and Md-2. J Biol Chem. (2001) 276:21129-35. doi: 10.1074/jbc.M009164200

103. Akira S, Takeda K. Toll-like receptor signalling. Nat Rev Immunol. (2004) 4:499-511. doi: 10.1038/nri1391

104. Chow JC, Young DW, Golenbock DT, Christ WJ, Gusovsky F. Toll-like receptor-4 mediates lipopolysaccharide-induced signal transduction. J Biol Chem. (1999) 274:10689-92. doi: 10.1074/jbc.274.16. 10689

105. Buchholz BM, Bauer AJ. Membrane Tlr signaling mechanisms in the gastrointestinal tract during sepsis. Neurogastroenterol Motil. (2010) 22:23245. doi: 10.1111/j.1365-2982.2009.01464.x
106. Zhang G, Ghosh S. Molecular mechanisms of Nf-Kappab activation induced by bacterial lipopolysaccharide through toll-like receptors. J Endotoxin Res. (2000) 6:453-7. doi: 10.1179/0968051001015 32414

107. Kawai T, Akira S. The role of pattern-recognition receptors in innate immunity: update on toll-like receptors. Nat Immunol. (2010) 11:373-84. doi: $10.1038 /$ ni.1863

108. Yu G-M, Kubota H, Okita M, Maeda T. The anti-inflammatory and antioxidant effects of melatonin on Lps-stimulated bovine mammary epithelial cells. PLoS ONE (2017) 12:E0178525. doi: 10.1371/journal.pone.0178525

109. Da Silveira Cruz-Machado S, Carvalho-Sousa CE, Tamura EK, Pinato L, Cecon E, Fernandes PA, et al. Tlr4 and Cd14 receptors expressed in rat pineal gland trigger $\mathrm{Nfkb}$ pathway. J Pineal Res. (2010) 49:183-92. doi: 10.1111/j.1600-079X.2010.0 0785.x

110. Wright SD, Ramos RA, Tobias PS, Ulevitch RJ, Mathison JC. Cd14, a receptor for complexes of lipopolysaccharide (Lps) and Lps binding protein. Science (1990) 249:1431-3. doi: 10.1126/science.16 98311

111. Morrey KM, Mclachlan JA, Serkin CD, Bakouche O. Activation of human monocytes by the pineal hormone melatonin. J Immunol. (1994) 153:267180.

112. Pioli C, Caroleo MC, Nistico G, Doria G. Melatonin increases antigen presentation and amplifies specific and non specific signals for T-cell proliferation. Int J Immunopharmacol. (1993) 15:463-8. doi: 10.1016/0192-0561(93)90060-C

113. Barjavel MJ, Mamdouh Z, Raghbate N, Bakouche O. Differential expression of the melatonin receptor in human monocytes. J Immunol. (1998) 160:1191.

114. Orton SM, Wald L, Confavreux C, Vukusic S, Krohn JP, Ramagopalan $\mathrm{SV}$, et al. Association of UV radiation with multiple sclerosis prevalence and sex ratio in France. Neurology (2011) 76:425-31. doi: 10.1212/WNL.0b013e31820a0a9f

115. Koch-Henriksen N, Sørensen PS. The changing demographic pattern of multiple sclerosis epidemiology. Lancet Neurol. (2010) 9:520-32. doi: 10.1016/S1474-4422(10)70064-8

116. Alonso A, Hernán MA. Temporal trends in the incidence of multiple sclerosis: a systematic review. Neurology (2008) 71:129-35. doi: 10.1212/01.wnl.0000316802.359 74.34

117. Wang Y, Marling SJ, Mcknight SM, Danielson AL, Severson KS, Deluca HF. Suppression of experimental autoimmune encephalomyelitis by 300-315nm ultraviolet light. Arch Biochem Biophys. (2013) 536:81-6. doi: 10.1016/j.abb.2013.05.010

118. Hart PH, Gorman S, Finlay-Jones JJ. Modulation of the immune system by UV radiation: more than just the effects of vitamin D? Nat Rev Immunol. (2011) 11:584-96. doi: 10.1038/nri3045

119. Kampman MT, Steffensen LH, Mellgren SI, Jørgensen L. Effect of vitamin D3 supplementation on relapses, disease progression, and measures of function in persons with multiple sclerosis: exploratory outcomes from a doubleblind randomised controlled trial. Multiple Scler J. (2012) 18:1144-51. doi: $10.1177 / 1352458511434607$

120. Rosjo E, Steffensen LH, Jorgensen L, Lindstrom JC, Saltyte Benth J, Michelsen AE, et al. Vitamin D supplementation and systemic inflammation in relapsing-remitting multiple sclerosis. J Neurol. (2015) 262:2713-21. doi: 10.1007/s00415-015-7902-5

121. Cantorna MT, Humpal-Winter J, Deluca HF. Dietary calcium is a major factor in 1,25-dihydroxycholecalciferol suppression of experimental autoimmune encephalomyelitis in mice. J Nutr. (1999) 129:1966-71. doi: $10.1093 /$ jn/129.11.1966

122. Irving AA, Marling SJ, Plum LA, Deluca HF. Suppression of experimental autoimmune encephalomyelitis by ultraviolet light is not mediated by isomerization of urocanic acid. BMC Neurosci. (2017) 18:8. doi: 10.1186/s12868-016-0323-2

123. Holick MF. Sunlight, UV-radiation, vitamin D and skin cancer: how much sunlight do we need? Adv Exp Med Biol. (2008) 624:1-15. doi: 10.1007/978-0-387-77574-6_1 
124. De Schepper HU, De Man JG, Van Nassauw L, Timmermans JP, Herman AG, Pelckmans PA, et al. Acute distal colitis impairs gastric emptying in rats via an extrinsic neuronal reflex pathway involving the pelvic nerve. Gut (2007) 56:195-202. doi: 10.1136/gut.2006.104745

125. Gangula PRR, Sekhar KR, Mukhopadhyay S. Gender bias in gastroparesis: is nitric oxide the answer? Digest Dis Sci. (2011) 56:2520-7. doi: 10.1007/s10620-011-1735-6

126. Chiuso-Minicucci F, Ishikawa LL, Mimura LA, Fraga-Silva TF, Franca TG, Zorzella-Pezavento SF, et al. Treatment with vitamin D/Mog association suppresses experimental autoimmune encephalomyelitis. PLoS ONE (2015) 10:E0125836. doi: 10.1371/journal.pone.0125836
Conflict of Interest Statement: The authors declare that the research was conducted in the absence of any commercial or financial relationships that could be construed as a potential conflict of interest.

Copyright $\odot 2018$ Ghareghani, Reiter, Zibara and Farhadi. This is an open-access article distributed under the terms of the Creative Commons Attribution License (CC $B Y)$. The use, distribution or reproduction in other forums is permitted, provided the original author(s) and the copyright owner(s) are credited and that the original publication in this journal is cited, in accordance with accepted academic practice. No use, distribution or reproduction is permitted which does not comply with these terms. 